\title{
Measurment of Copper Concentration in ACQ, CUAZ, and CB-HDO Solutions by Using a Spectrophotometer*1
}

\author{
Jong-Bum $\mathrm{Ra}^{* 2}$
}

\begin{abstract}
This research was performed to develop the simple techniques to predict the copper concentration in alkaline copper quat (ACQ), copper azole (CUAZ), and bis-(N-cyclohexyl-diazeniumdioxy)-copper (CB-HDO) solutions. Two simple methods measuring the color due to copper compounds were evaluated by using a spectrophotometer. One is to directly measure the color of the preservative solutions. The other is to measure the color developed on the surface of a treated sample with the preservatives. The $\mathrm{L}^{*}$ of the measured color values appeared to be the most sensitive to the change of copper concentration. The $a^{*}$ values of the preservative solutions tended to be decreased at above a certain concentration condition, and the $b^{*}$ values showed no trend with the concentration of copper compounds in preservative solutions. The surface color of the treated samples were changed from bluish to greenish as time passed. Both methods showed the high $\mathrm{R}^{2}$ values of the regression models determined by using the lightness, which suggested that the methods might be applicable in preservative-treatment mills for the easy and fast prediction of the copper concentration.
\end{abstract}

Keywords : ACQ, CB-HDO, CUAZ, copper concentration

\section{INTRODUCTION}

Wood preservation industry in Korea have replaced chromated copper arsenate (CCA) with copper-based wood preservatives such as alkaline copper quat (ACQ), copper azole, and (CUAZ) bis(N-cyclohexyl-diazeniumdioxy)-copper (CB-HDO) since the use and manufacture of CCA were banned in Korea. The copper-based wood preservatives have obtained good recognition because of the performance and effectiveness against wood decay fungi and the absence of arsenic and chrome (Freeman and McIntyre, 2008; Lebow et al., 2004; Manriquez et al., 1996). However, the increase of environmental concerns of the possible environmental impact caused by unfixed active ingredients in the treated wood has forced wood preservation industry to perform the more careful quality control in producing the treated woods (Kang et al., 2008; Jiang and

*1 Received on June 22, 2010; accepted on August 14, 2010

*2 Department of Interior Materials Engineering, College of Sciences and Engineering, Jinju National University, Jinju, Kyungnam 660-758, Korea

† Corresponding author : Jong-Bum Ra (e-mail : jb@jinju.ac.kr) 
Measurment of Copper Concentration in ACQ, CUAZ, and CB-HDO Solutions by Using a Spectrophotometer

Table 1. Composition (wt\%) of active ingredients in ACQ-2, CUAZ-2, and CB-HDO

\begin{tabular}{cccccc}
\hline \multicolumn{2}{c}{ ACQ-2 } & \multicolumn{2}{c}{ CUAZ-2 } & \multicolumn{2}{c}{ CB-HDO } \\
\hline \hline & & & $\mathrm{CuO}$ & $60-68$ \\
$\mathrm{CuO}$ & $62.0-71.0$ & $\mathrm{CuO}$ & $98.6-99.0$ & $\mathrm{H}_{3} \mathrm{BO}_{3}$ & $20-22$ \\
$\mathrm{DDAC}$ & $29.0-38.0$ & Cyproconasole & $1.0-1.4$ & $\mathrm{HDO}$ & $14-16$ \\
\hline
\end{tabular}

Ruddick, 2004).

The quality control in producing preservative treated woods begins with the precise control of the concentration of preservative solutions. Unfortunately, most of wood preservative treatment mills in Korea do not have their own methods or techniques to check the solution strength precisely. They regularly check the solution strength by sending the samples to Korea Forest Research Institute (KFRI) for the analysis. However, it can not be practically used for the purpose of quality control because it takes too much time to get the results. Therefore, the development of easy techniques to measure the solution strengths in the field must be an important step to produce the treated wood with excellent quality.

The color of preservative solutions may be useful to develop the technique to measure the solution strength especially for the copper-containing wood preservatives because they show blue or green colors due to their copper compounds. The currently used wood preservatives in Korea such as ACQ, CUAZ, and CB-HDO contains copper compounds. The rest of active ingredients such as didecyldimethyl ammonium chloride (DDAC) in ACQ, tebuconazole in CUAZ, and borate compounds in CB-HDO does not develop any color to the treatment solution or the treated wood (U. S. Borax and Chemical Corp., 1986). Therefore, the color of ACQ, CUAZ, and CB-HDO is affected on the change of copper concentration.

The objective of this research is to develop the easy techniques to measure the copper con- centration in ACQ, CUAZ, and CB-HDO solutions. The color of the preservative solutions and the treated sample surface were measured by using a spectrophotometer. The applicability of the methods on the prediction of copper concentration were evaluated.

\section{MATERIALS and METHODS}

\subsection{Preparation of Copper-Containing Wood Preservatives}

Alkaline copper quat-type 2 (ACQ-2), copper azole-type 2 (CUAZ-2), and bis-(N-cyclohexyldiazeniumdioxy)-copper (CB-HDO) were used in this research. The percents of total active ingredients in the obtained ACQ-2, CUAZ-2, and CB-HDO were $16 \%, 12 \%$, and $25 \%$, respectively (Table 1.). The preservatives were diluted to various concentrations by adding distilled water.

\subsection{Color Measurement}

Two methods were tested to develop the simple technique to predict the solution strength. One is to directly measure the color of the prepared preservative solutions. The transmittance of the prepared solutions at various concentration conditions were measured by a spectrophotometer (Minolta CM-3600d) which employs the $\mathrm{d} / 0^{\circ}$ geometry (diffused lighting, $0^{\circ}$ viewing). The thickness of a cell (CM-A98) is $10 \mathrm{~mm}$.

The other is to measure the color developed on the surface of a treated object such as paper 
Jong-Bum Ra

Table 2. The measured transmittance of the various concentrations of copper-containing preservatives

\begin{tabular}{|c|c|c|c|c|c|c|c|c|c|c|c|}
\hline \multicolumn{4}{|c|}{ ACQ } & \multicolumn{4}{|c|}{ CUAZ } & \multicolumn{4}{|c|}{ CB-HDO } \\
\hline$\% \mathrm{CuO}$ & $\mathrm{L}^{*}$ & $\mathrm{a}^{*}$ & $\mathrm{~b}^{*}$ & $\% \mathrm{CuO}$ & $\mathrm{L}^{*}$ & $\mathrm{a}^{*}$ & $\mathrm{~b}^{*}$ & $\% \mathrm{CuO}$ & $\mathrm{L}^{*}$ & $\mathrm{a}^{*}$ & $\mathrm{~b}^{*}$ \\
\hline $0.072^{* 1}$ & 71.66 & 1.07 & -31.65 & 0.068 & 48.97 & 3.66 & -65.83 & 0.279 & 56.10 & 10.35 & -48.53 \\
\hline 0.099 & 50.82 & 11.92 & -55.79 & 0.271 & 33.03 & 34.32 & -80.45 & 1.064 & 33.21 & 35.23 & -71.21 \\
\hline 0.223 & 39.20 & 24.81 & -67.45 & 0.520 & 24.68 & 50.87 & -82.76 & 1.115 & 21.64 & 54.79 & -78.29 \\
\hline 0.337 & 30.05 & 39.09 & -74.77 & 0.587 & 19.61 & 57.83 & -81.20 & 1.236 & 14.85 & 65.21 & -78.64 \\
\hline 0.448 & 24.06 & 49.28 & -77.78 & 0.857 & 16.10 & 60.91 & -78.84 & 1.461 & 10.75 & 68.56 & -76.04 \\
\hline 0.569 & 19.43 & 56.85 & -78.69 & 0.959 & 13.24 & 62.14 & -75.99 & 1.744 & 7.92 & 68.66 & -72.67 \\
\hline 0.666 & 16.19 & 61.08 & -78.05 & 1.039 & 10.46 & 60.41 & -71.42 & 1.990 & 5.98 & 66.48 & -68.84 \\
\hline 0.758 & 13.43 & 63.80 & -76.61 & 1.240 & 8.72 & 60.11 & -69.00 & 2.373 & 4.60 & 62.32 & -64.34 \\
\hline 0.854 & 11.11 & 64.88 & -74.55 & 1.334 & 7.02 & 57.33 & -65.10 & 2.620 & 3.91 & 59.24 & -61.42 \\
\hline 0.921 & 9.41 & 64.67 & -72.32 & 1.451 & 5.75 & 54.43 & -61.56 & 2.884 & 3.02 & 53.62 & -56.61 \\
\hline
\end{tabular}

${ }^{* 1}$ Values are the concentration of copper $(\% \mathrm{CuO})$ in the tested wood preservatives.

${ }^{*}$ Values represent means of five replicates.

or wood with the preservatives. In this research, a sheet of No. 4 filter paper was immersed in each of $300 \mathrm{ml}$ of the prepared solution for five minutes. Because filter papers have uniform porosities, they are considered to uniformly absorb the active ingredients in the prepared solutions. Five minutes after the immersion, the treated samples were air-dried at room temperature. The reflectance of the treated samples were measured by the spectrophotometer employing the $\mathrm{d} / 8^{\circ}$ geometry (diffused lighting, $8^{\circ}$ from normal viewing).

The transmittance of preservative solutions and the surface color of treated samples were measured in the $\mathrm{L}^{*} \mathrm{a} \mathrm{b}^{*}$ color space. In the color space, $\mathrm{L}^{*}$ indicates lightness (the value on the white/black axis) and $\mathrm{a}^{*}$ (the value on the red/green axis) and $b^{*}$ (the value on the blue/yellow axis) are the chromaticity coordinates.

\subsection{Analysis of Copper}

The copper contents in the prepared solutions were analyzed by using a flame atomic absorption spectrometer (Shimadzu AA-6800) in an air-acetylene flame. The lamp currents, wavelengths, slit widths, and linear calibration rages are $6 \mathrm{~mA}, 324.8 \mathrm{~nm}, 0.5 \mathrm{~nm}$, and $0.5 \sim 10 \mathrm{ppm}$, respectively.

\subsection{Data Analysis}

Correlation analysis between the measured values of $L^{*}, a^{*}$, and $b^{*}$ values and the copper concentration in the wood preservative solutions were performed. The concentration of other active ingredients were assumed to have no effect on the color of the wood preservatives.

\section{RESULTS and DISCUSSION}

The values of measured transmittance of the prepared ACQ, CUAZ, and CB-HDO solutions at various concentrations are shown in Table 2. The color of the prepared preservative solutions were darker with the increase of solution concentration. In the given concentration conditions, the values of measured $\mathrm{L}^{*}$ and $\mathrm{a}^{*}$ were positive and the values of $b^{*}$ were negative. As 
Measurment of Copper Concentration in ACQ, CUAZ, and CB-HDO Solutions by Using a Spectrophotometer

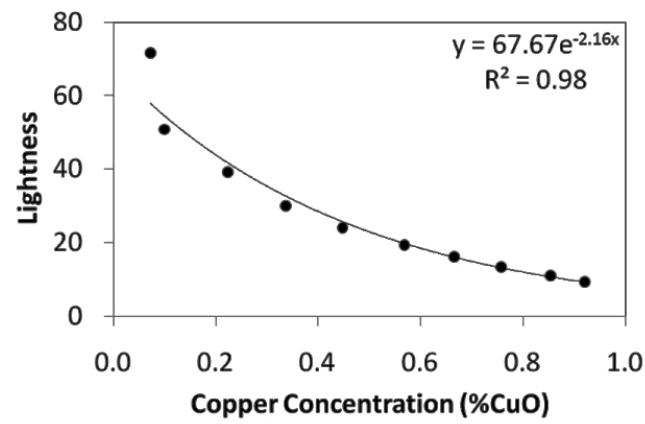

(A) ACQ

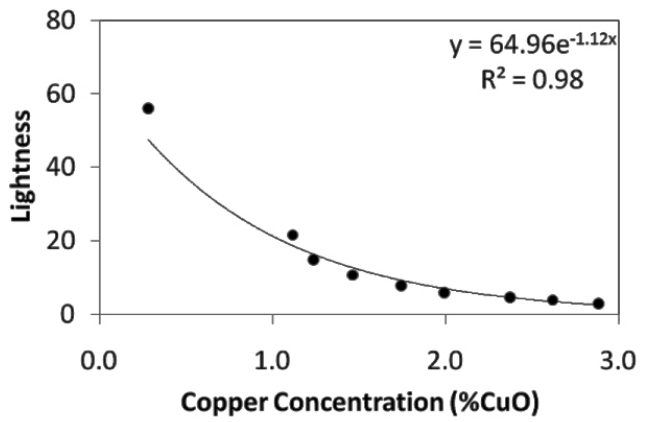

(B) CB-HDO

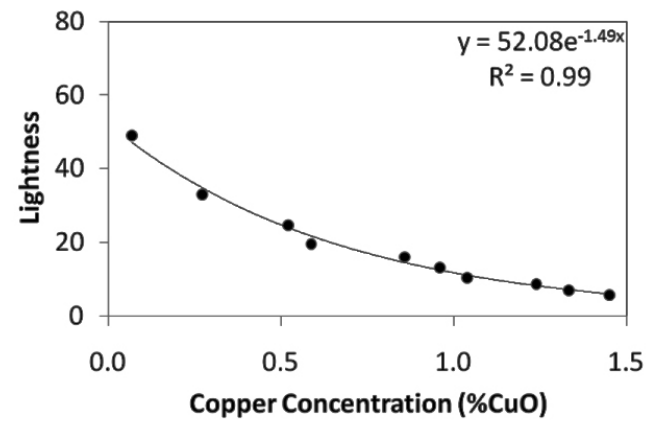

(C) CUAZ

Fig. 1. The relation between the lightness and copper concentration of ACQ, CUAZ, and CB-HDO solutions.

expected the $\mathrm{L}^{*}$ values were decreased and the $\mathrm{a}^{*}$ values were increased with the increase of copper concentration. The positive $b^{*}$ values mean that the preservative solutions show blue colors.

The $L^{*}$ values appeared to be the most sensitive to the change of copper concentration than the $a^{*}$ and $b^{*}$ values (Fig. 1). The $a^{*}$ values tended to be decreased at above a certain concentration conditions, and the $b^{*}$ values showed no trends with the concentration of copper compounds in preservative solutions. In all preservative solutions, the $R^{2}$ values determined from the relation between $\mathrm{L}^{*}$ and copper concentration were above 0.98 , meaning that the copper concentration could be predicted using the $\mathrm{L}^{*}$ of preservative solution.

The measured colors of the treated samples with the various concentration conditions of ACQ, CUAZ, and CB-HDO solutions are shown in Table 3. The increase of copper concentration resulted in the decrease in the values of $L^{*}, a^{*}$, and $b^{*}$. The values of standard deviation is low, meaning the colors on the sample surface were uniformly developed after $5 \mathrm{mi}$ nutes immersion. The measured $\mathrm{a}^{*}$, and $\mathrm{b}^{*}$ values appeared to be proportionally decreased with the increased copper concentration, when compared with the transmittance.

The bluish color on the sample surface after the treatment were changed to greenish with the increase of time, meaning the change of the $a^{*}$ and $b^{*}$ values with time. However, the values of lightness showed no change with the time. Therefore, the lightness was thought to be the most useful factor to predict the copper concentration. 
Jong-Bum Ra

Table 3. The measured colors of the treated samples immersed in the various concentrations of ACQ, CUAZ, and CB-HDO

\begin{tabular}{|c|c|c|c|c|c|c|c|c|c|c|c|}
\hline \multicolumn{4}{|c|}{ ACQ } & \multicolumn{4}{|c|}{ CUAZ } & \multicolumn{4}{|c|}{ CB-HDO } \\
\hline$\% \mathrm{CuO}$ & $\mathrm{L}^{*}$ & $a^{*}$ & $\mathrm{~b}^{*}$ & ${ }_{0} \mathrm{CuO}$ & $L^{*}$ & $a^{*}$ & $b^{*}$ & $\% \mathrm{CuO}$ & $\mathrm{L}^{*}$ & $a^{*}$ & $b^{*}$ \\
\hline $0.072^{* 1}$ & $\begin{array}{c}87.47^{* 2} \\
(0.068)^{* 3}\end{array}$ & $\begin{array}{c}-3.55 \\
(0.068)\end{array}$ & $\begin{array}{c}-0.89 \\
(0.030)\end{array}$ & 0.068 & $\begin{array}{c}84.77 \\
(0.182)\end{array}$ & $\begin{array}{c}-2.98 \\
(0.042)\end{array}$ & $\begin{array}{c}-8.00 \\
(0.227)\end{array}$ & 0.279 & $\begin{array}{c}85.73 \\
(0.107)\end{array}$ & $\begin{array}{c}-3.42 \\
(0.066)\end{array}$ & $\begin{array}{c}-2.75 \\
(0.015)\end{array}$ \\
\hline 0.099 & $\begin{array}{c}85.12 \\
(0.207)\end{array}$ & $\begin{array}{l}-5.33 \\
(0.125)\end{array}$ & $\begin{array}{l}-2.15 \\
(0.109)\end{array}$ & 1 & $\begin{array}{c}80.08 \\
(0.300)\end{array}$ & $\begin{array}{l}-3.92 \\
(0.052)\end{array}$ & $\begin{array}{l}-13.67 \\
(0.260)\end{array}$ & 1.064 & $\begin{array}{c}80.42 \\
(0.399)\end{array}$ & $\begin{array}{c}-6.42 \\
(0.249)\end{array}$ & $\begin{array}{c}-4.53 \\
(0.036)\end{array}$ \\
\hline 0.22 & $\begin{array}{c}82.56 \\
(0.573)\end{array}$ & $\begin{array}{c}-6.93 \\
(0.299)\end{array}$ & $\begin{array}{c}-3.29 \\
(0.237)\end{array}$ & 0.520 & $\begin{array}{l}77.98 \\
(0.215)\end{array}$ & $\begin{array}{l}-4.18 \\
(0.022)\end{array}$ & $\begin{array}{l}-16.26 \\
(0.250)\end{array}$ & 5 & $\begin{array}{c}78.06 \\
(0.214)\end{array}$ & $\begin{array}{c}-7.70 \\
(0.130)\end{array}$ & $\begin{array}{c}-5.33 \\
(0.098)\end{array}$ \\
\hline 0.337 & $\begin{array}{c}80.98 \\
(0.215)\end{array}$ & $\begin{array}{c}-7.68 \\
(0.116)\end{array}$ & $\begin{array}{c}-3.75 \\
(0.064)\end{array}$ & 0.587 & $\begin{array}{c}76.34 \\
(0.310)\end{array}$ & $\begin{array}{c}-4.19 \\
(0.017)\end{array}$ & $\begin{array}{l}-18.15 \\
(0.322)\end{array}$ & 1.236 & $\begin{array}{c}73.78 \\
(0.225)\end{array}$ & $\begin{array}{c}-9.74 \\
(0.111)\end{array}$ & $\begin{array}{c}-5.84 \\
(0.095)\end{array}$ \\
\hline 0.44 & $\begin{array}{c}79.61 \\
(0.264)\end{array}$ & $\begin{array}{l}-8.25 \\
(0.150)\end{array}$ & $\begin{array}{c}-4.30 \\
(0.121)\end{array}$ & 0.857 & $\begin{array}{c}74.75 \\
(0.560)\end{array}$ & $\begin{array}{c}-4.19 \\
(0.034)\end{array}$ & $\begin{array}{l}-19.95 \\
(0.540)\end{array}$ & 1 & $\begin{array}{c}72.14 \\
(0.152)\end{array}$ & $\begin{array}{l}-10.43 \\
(0.074)\end{array}$ & $\begin{array}{c}-6.30 \\
(0.154)\end{array}$ \\
\hline 0.569 & $\begin{array}{c}76.93 \\
(0.386)\end{array}$ & $\begin{array}{c}-9.53 \\
(0.179)\end{array}$ & $\begin{array}{c}-5.29 \\
(0.185)\end{array}$ & 0.959 & $\begin{array}{l}72.30 \\
(0.33)\end{array}$ & $\begin{array}{c}-4.04 \\
(0.029)\end{array}$ & $\begin{array}{l}-22.63 \\
(0.294)\end{array}$ & 1.744 & $\begin{array}{c}71.21 \\
(0.251)\end{array}$ & $\begin{array}{l}-10.91 \\
(0.115)\end{array}$ & $\begin{array}{c}-6.44 \\
(0.053)\end{array}$ \\
\hline 0.666 & $\begin{array}{c}77.29 \\
(0.437)\end{array}$ & $\begin{array}{c}-9.33 \\
(0.178)\end{array}$ & $\begin{array}{c}-5.12 \\
(0.184)\end{array}$ & 1.0 & $\begin{array}{c}69.53 \\
(0.300)\end{array}$ & $\begin{array}{l}-3.86 \\
(0.035)\end{array}$ & $\begin{array}{l}-25.31 \\
(0.237)\end{array}$ & 1.990 & $\begin{array}{c}69.88 \\
(0.320)\end{array}$ & $\begin{array}{l}-11.53 \\
(0.123)\end{array}$ & $\begin{array}{c}-5.37 \\
(0.145)\end{array}$ \\
\hline 0.758 & $\begin{array}{c}74.68 \\
(0.244)\end{array}$ & $\begin{array}{l}-10.40 \\
(0.107)\end{array}$ & $\begin{array}{c}-5.91 \\
(0.053)\end{array}$ & 1. & $\begin{array}{c}68.63 \\
(0.194)\end{array}$ & $\begin{array}{c}-3.66 \\
(0.040)\end{array}$ & $\begin{array}{l}-26.45 \\
(0.144)\end{array}$ & 2.373 & $\begin{array}{c}68.94 \\
(0.442)\end{array}$ & $\begin{array}{l}-11.90 \\
(0.171)\end{array}$ & $\begin{array}{c}-6.47 \\
(0.162)\end{array}$ \\
\hline 0.854 & $\begin{array}{c}74.49 \\
(0.157)\end{array}$ & $\begin{array}{l}-10.62 \\
(0.044)\end{array}$ & $\begin{array}{c}-6.26 \\
(0.060)\end{array}$ & 1.334 & $\begin{array}{c}67.83 \\
(0.363)\end{array}$ & $\begin{array}{c}-3.64 \\
(0.052)\end{array}$ & $\begin{array}{l}-26.96 \\
(0.26)\end{array}$ & 2.620 & $\begin{array}{c}68.04 \\
(0.128)\end{array}$ & $\begin{array}{l}-12.32 \\
(0.06)\end{array}$ & $\begin{array}{l}-5.96 \\
(0.08)\end{array}$ \\
\hline 0.921 & $\begin{array}{c}73.79 \\
(0.695)\end{array}$ & $\begin{array}{l}-10.74 \\
(0.266)\end{array}$ & $\begin{array}{c}-6.26 \\
(0.243)\end{array}$ & 1 & $\begin{array}{l}66.91 \\
(0.28)\end{array}$ & $\begin{array}{l}-3.62 \\
(0.035)\end{array}$ & $\begin{array}{l}-27.71 \\
(0.19)\end{array}$ & 34 & $\begin{array}{c}66.46 \\
(0.221)\end{array}$ & $\begin{array}{l}-12.83 \\
(0.088)\end{array}$ & $\begin{array}{l}-5.814 \\
(0.052)\end{array}$ \\
\hline
\end{tabular}

${ }^{*}$ Values are the concentration of copper $(\% \mathrm{CuO})$ in the tested wood preservatives.

${ }^{*}$ Values represent means of five replicates.

${ }^{* 3}$ Values represent the standard deviation.

The color change of treated sample could be explained by the oxidation process of copper compounds. The $\mathrm{R}^{2}$ values of the linear regression models to predict the copper concentration of ACQ, and CUAZ are above 0.95, and the $\mathrm{R}^{2}$ values of the CB-HDO model is about 0.88 (Fig. 2).

The methods used in this research can not tell what types of preservatives are used for the treatment. But they showed the possibility in predicting the copper concentration of ACQ, CUAZ, and CB-HDO solutions in the conditions that the preservative types used for the treatment are known. All preservative wood used in Korea can be placed into one of five major use categories ( $\mathrm{H} 1$ to $\mathrm{H} 5)$ that clearly describe the preservative systems and retentions that is effective in protecting wood products un- 
Measurment of Copper Concentration in ACQ, CUAZ, and CB-HDO Solutions by Using a Spectrophotometer

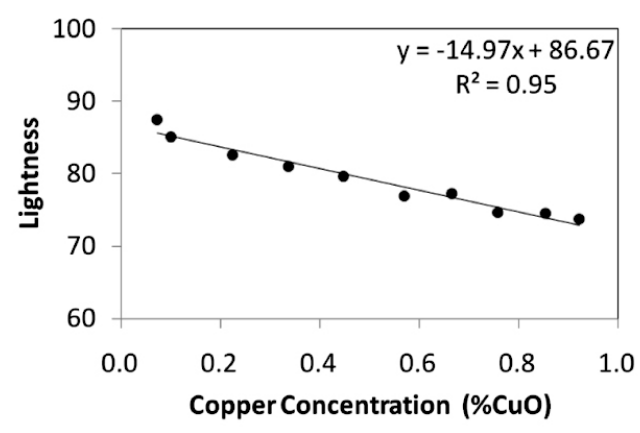

(A) ACQ

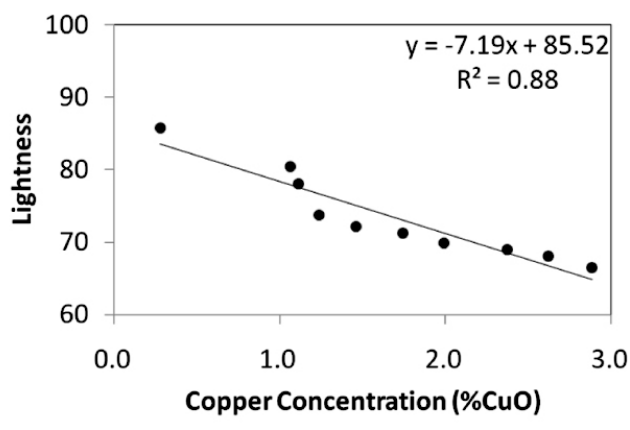

(B) CB-HDO

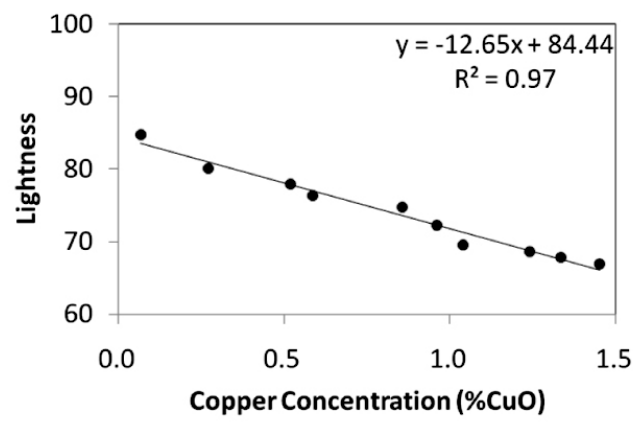

(C) CUAZ

Fig. 2. The relation between the lightness of the treated samples and the copper concentrations in ACQ, CUAZ, and $\mathrm{CB}-\mathrm{HDO}$ solutions.

der specified exposure conditions that specific wood products can be subjected to in service. The retention of treated wood exceeding the required level means the use of excess preservatives, resulting in economical loss as well as the increase of environmental impacts. From this point of view, the quality control of preservative concentration according to the use categories is important to the treatment plants. The methods used in this research is thought to be applicable in the treatment mills for the practical purpose because the easy and fast measurement of copper concentration in ACQ, CUAZ, and CB-HDO solutions is possible.

\section{CONCLUSIONS}

The copper concentration in ACQ, CUAZ, and CB-HDO solutions can be predicted by measuring the color of the preservative solutions, and the surface color of treated samples. The $\mathrm{L}^{*}$ values appeared to be the most sensitive to the change of copper compounds than the $\mathrm{a}^{*}$ and $b^{*}$ values. The methods used in this research can not distinguish preservative types used for the treatment. But, given the conditions of knowing the preservative types used for the treatment, the methods may be applicable for the quality control of ACQ, CUAZ, and CB-HDO solutions in treatment mills because of the easy 
and fast measurement of copper concentration.

\section{ACKNOWLEDGMENTS}

This study was supported by Jinju National University 2010 grant.

\section{REFERENCES}

1. Freeman, M. H. and C. R. McIntyre. 2008. A comprehesive review of copper-based wood preservatives with a focus on new micronized or dispersed copper systems. Forest Products Journal 58(11): $6 \sim 27$.

2. Jiang, X. and J. N. R. Ruddick. 2004. Leaching re- sistance of copper amine-treated Scots pine. Forest Products Journal 54(12): 213 216.

3. Kang, S. M., I. Y. Hwang, and S. K. Kim. 2008. Effect of steam on fixation of $\mathrm{Cu}$-amine preservative treated wood. Int. Res. Group on Wood Pres. Document No: IRG/WP 08-50251.

4. Lebow, S., J. Winandy, and D. Bender. 2004. Treated wood in transition; A look at CCA and the candidates to replace it. Wood design Focus. Summer 2004. $4 \sim 8$.

5. Manriquez, V., M. C. Vallette, N. Lara, N. G. Tejeda, O. Wittke, G. Diaz, S. Munoz, and L. Kriskovic. 1996. Crystal structure and vibrational spectra of polyamine-copper (II) complexes. J. Chem. Crystal. 26(1): $15 \sim 22$.

6. U. S. Borax and Chemical Corp. 1986. TIM-BOR ${ }^{\circledR}$ Preservative Plant Operators' Mannual. 